\title{
MECHANISTIC STUDIES OF COMBUSTION AND STRUCTURE FORMATION DURING SYNTHESIS OF ADVANCED MATERIALS
}

\author{
A. Varma, C. Lau and A.S. Mukasyan \\ Department of Chemical Engineering, and Center for Molecularly Engineered Materials \\ University of Notre Dame, Notre Dame, IN 46556, USA
}

\section{INTRODUCTION}

Combustion in a variety of heterogeneous systems, leading to the synthesis of advanced materials [1-4], is characterized by high temperatures (2000-3500 K) and heating rates (up to $10^{6} \mathrm{~K} / \mathrm{s}$ ) at and ahead of the reaction front. These high temperatures generate liquids and gases which are subject to gravity-driven flow. The removal of such gravitational effects is likely to provide increased control of the reaction front, with a consequent improvement in control of the microstructure of the synthesized products. Thus, microgravity $(\mu \mathrm{g})$ experiments lead to major advances in the understanding of fundamental aspects of combustion and structure formation under the extreme conditions of the combustion synthesis (CS) wave. In addition, the specific features of microgravity environment allow one to produce unique materials, which cannot be obtained under terrestrial conditions. The current research is a logic continuation of our previous work [cf.5, 6] on investigations of the fundamental phenomena of combustion and structure formation that occur at the high temperatures achieved in a CS wave.

Our research is being conducted in three main directions:

1. Microstructural Transformations during Combustion Synthesis of Metal-Ceramic Composites. The studies are devoted to the investigation of particle growth during CS of intermetallic-ceramic composites, synthesized from nickel, aluminum, titanium, and boron metal reactants. To determine the mechanisms of particle growth, the investigation varies the relative amount of components in the initial mixture to yield combustion wave products with different ratios of solid and liquid phases, under $1 \mathrm{~g}$ and $\mu \mathrm{g}$ conditions.

2. Mechanisms of Heat Transfer during Reactions in Heterogeneous Media. Specifically, new phenomena of gasless combustion wave propagation in heterogeneous media with porosity higher than that achievable in normal gravity conditions, are being studied. Two types of mixtures are investigated: clad powders, where contact between reactants occurs within each particle, and mixtures of elemental powders, where interparticle contacts are important for the reaction.

3. Mechanistic Studies of Phase Separation in Combustion of Thermite Systems. Studies are devoted to experiments on thermite systems (metal oxide-reducing metal) where phase separation processes occur to produce alloys with tailored compositions and properties. The separation may be either gravity-driven or due to surface forces, and systematic studies to elucidate the true mechanism are being conducted.

The knowledge obtained will be used to find the most promising ways of controlling the microstructure and properties of combustion-synthesized materials. Low-gravity experiments are essential to create idealized an environment for insights into the physics and chemistry of advanced material synthesis processes. 


\section{EXPERIMENTAL}

The sample was placed in the reaction chamber, which was evacuated $\left(10^{-2} \mathrm{~atm}\right)$ and then filled with inert gas (high purity argon) up to $1 \mathrm{~atm}$. An electrically heated tungsten coil initiated the combustion reaction, typically from bottom of the sample. A microcomputer (Tattletale) synchronized ignition and temperature measurements, with the experimental conditions (e.g. gravity). Combustion front propagation was recorded through a quartz window by using video camera (SONY CCD-IRIS). The velocity of combustion front propagation was determined by statistical analysis of the obtained video images (30 frames/s). A two-color infrared pyrometer (IRCON MIRAGE, MR-OR10-99C10) and thermocouples (W-Re 5/26) were used to measure the sample temperature-time history. The details of the experimental setup and procedure are described elsewhere [cf.5].

Quenching, which involves rapid cooling of the combustion front, was utilized to investigate the mechanisms of microstructural transformation taking place during CS. Different quenching methods have been reported and their intrinsic limitations have been discussed in the literature [cf.7]. In the present work, the most efficient method, i.e. quenching by massive copper block was used. After quenching, the phase composition and microstructures in different zones of the combustion wave were identified using layer-by-layer analysis of the sample from its tip (initial mixture) to the top (final product), to elucidate the evolution of material structure formation during CS. These microstructures were analyzed using scanning electron microscopy (SEM, JEOL 6400) along with energy dispersive X-ray spectrometry (EDXS, KEVEX) and advanced image analysis software (TMAGE PRO-PLUS 4.0).

All experiments were conducted identically in both terrestrial $(1 \mathrm{~g})$ and microgravity $\left(10^{-2} \mathrm{~g}\right)$ conditions to make direct comparison and to identify the role of gravity on mechanism of combustion and microstructure formation. Microgravity experiments were conducted during parabolic flights of $\mathrm{KC}-135$ aircraft in NASA Glenn Research Center, Cleveland, $\mathrm{OH}$, providing microgravity environment $\left(\sim 10^{-2} \mathrm{~g}\right)$ for about $20 \mathrm{~s}$.

\section{RESULTS AND DIUSCUSSION}

\section{Microstructural Transformations during Combustion Synthesis of Metal-Ceramic Composites}

Combustion synthesis of NiAl-based materials reinforced by $\mathrm{TiB}_{2}$ particles was investigated under both $1 \mathrm{~g}$ and $\mu \mathrm{g}$ conditions [8]. It was shown that the synthesized metal matrix composites (MMC) are characterized by fine $(<1 \mu \mathrm{m})$ reinforced particulate, which have strong bonding along their entire surface with matrix (NiAl) and are distributed uniformly in it. It was also found that $\mu \mathrm{g}$ leads to a decrease in the average $\mathrm{TiB}_{2}$ particle size, while higher volume fraction of $\mathrm{NiAl}$ component in the material leads to the formation of coarser reinforced particulates. The results of statistical analysis on average size, $d$, of $\mathrm{TiB}_{2}$ grains for different compositions are presented in Table I.

Table I. Average grain size of $\mathbf{T i B}_{2}$ after CS under different gravity conditions

\begin{tabular}{c|cc|cc}
\hline \multirow{2}{*}{$\begin{array}{c}\text { Volume fraction of } \mathrm{TiB}_{2} ; \\
\text { Mole ratio } \mathrm{TiB}_{2} / \mathrm{NiAl}^{2}\end{array}$} & $\begin{array}{c}\text { Terrestrial } \\
\text { Average grain size, }\end{array}$ & $\begin{array}{c}\sigma \\
\text { Merage grain size, }\end{array}$ & $\begin{array}{c}\sigma \\
\text { Averagry }\end{array}$ \\
\hline $23 \% ; 1 / 4$ & $\mu \mathrm{m}$ & $\mu \mathrm{m}$ & $\mu \mathrm{m}$ & $\mu \mathrm{m}$ \\
$26 \% ; 1 / 3.5$ & 0.65 & 0.32 & 0.50 & 0.27 \\
$33 \% ; 1 / 2.5$ & 0.44 & 0.15 & 0.42 & 0.14 \\
\hline
\end{tabular}


It can be seen that $d$ is generally smaller for materials synthesized under microgravity. The standard deviation $\sigma$, characterizing the uniformity of grain size distribution, is also somewhat smaller for materials formed under $10^{-2} \mathrm{~g}$ conditions. Thus finer and more uniform microstructures are obtained under reduced gravity. However, the influence of gravity is less pronounced for compositions with smaller volume fraction of $\mathrm{NiAl}$ matrix.

The mechanism of structure formation of different MMCs during CS was identified by using the quenching technique. Statistical analysis of typical microstructures and phase compositions in different cross-sections of quenched samples revealed that the process of microstructure formation during CS can in general be divided into four zones, which are characterized as follows:

Zone 1: reaction between $\mathrm{Ni}$ and $\mathrm{Al}$ with formation of primarily $\mathrm{NiAl}$ phase, while $\mathrm{Ti}$ and $\mathrm{B}$ remain essentially unreacted;

Zone 2: dissolution of $\mathrm{Ti}$ and $\mathrm{B}$ in NiAl phase with formation of complex Ni-Al-Ti-B solution;

Zone 3: crystallization of solid $\mathrm{TiB}_{2}$ particles from the solution and their growth in NiAl-rich liquid matrix;

Zone 4: growth and uniform dispersion of $\mathrm{TiB}_{2}$ particles in $\mathrm{NiAl}$ matrix, to yield the final product.

All zones described above were qualitatively present in all samples synthesized in both $1 \mathrm{~g}$ and $\mu \mathrm{g}$ conditions. However, the characteristic length of each zone in samples reacted under microgravity was larger as compared with terrestrial product (see Table II). Thus, an overall decrease of microstructural transformation rates was observed under $\mu \mathrm{g}$.

Table II. The length of characteristic microstructural zones $\left(\mathrm{TiB}_{2} / \mathrm{NiAl}=1 / 4\right)$

\begin{tabular}{ccc}
\hline Zone & $\begin{array}{c}\text { Terrestrial } \\
\mathbf{L}, \boldsymbol{\mu m}\end{array}$ & $\begin{array}{c}\text { Microgravity } \\
\mathbf{L}, \boldsymbol{\mu m}\end{array}$ \\
\hline 1 & 300 & 400 \\
2 & 4700 & 5850 \\
3 & 3250 & 4250 \\
\hline
\end{tabular}

\section{Mechanisms of Heat Transfer during Reactions in Heterogeneous Media}

It was shown that combustion of complex clad particles, where one metal forms the core (Al) while the other constitutes the shell (Ni), exhibits novel phenomena. It has been demonstrated by experiments conducted under weightless conditions in drop tower [5] and during parabolic flights on DC-9 aircraft [6], as well as confirmed by studies made in "MIR" space station [9], that it is possible to organize a so-called contactless combustion regime [10] with such particles, where radiation heat transfer controls the process. In this case, we showed [11] that by changing density of the reaction mixture, the mechanism of heat transfer which controls the reaction front propagation can be varied: radiation for low densities (in $\mu \mathrm{g}$ conditions), gas heat conduction for intermediate values, and heat conduction through condensed skeleton for high sample densities (see Figure 1).

Further, the process of outer shell cracking plays an important role in the mechanism of combustion wave propagation. On one hand, more refractory shell $(\mathrm{Ni})$ prevents the reaction medium from rapid agglomeration, while on the other hand, cracking of the shell followed by spreading of molten Al ahead of the front is important for combustion wave propagation in this system. The results suggest that combustion of complex particles with different initial densities including particle clouds) should be investigated under different oxidizing atmospheres, and this is planned for the near future. 


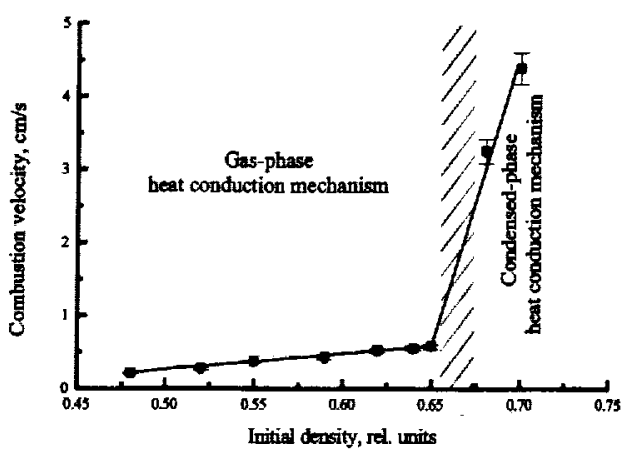

(a)

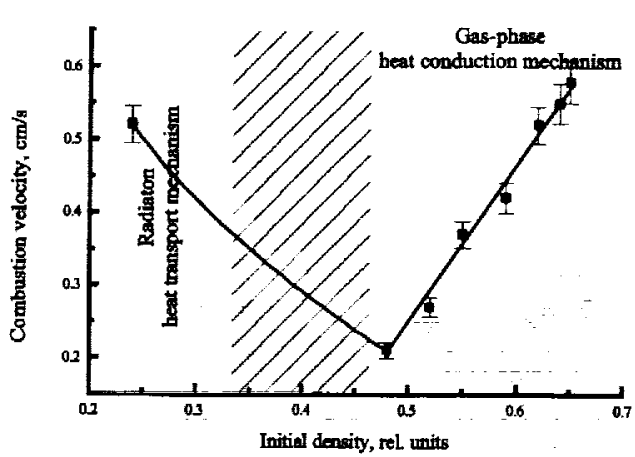

(b)

Figure 1. The dependence of combustion velocity on sample intial density.

\section{Mechanistic Studies of Phase Separation in Combustion of Thermite Systems}

Studies are devoted to experiments on thermite systems (metal oxide-reducing metal) where phase separation processes occur to produce alloys with tailored compositions and properties. Such reaction systems are important in various applications, including production of orthopedic implant materials. Due to high reaction exothermicity, the process results in a significant increase of temperature (up to $3000^{\circ} \mathrm{C}$ ) which is higher than melting points of all products. Since the products differ in density, phase separation may be a gravity-driven process: the heavy (metallic phase) settles while the light (slag) phase floats. However, our preliminary experiments demonstrate that a high degree of phase separation also occurs under $\mu \mathrm{g}$ conditions. Thus it is necessary to conduct more detailed research to elucidate the true mechanism of this phenomenon.

Three reaction systems $\left(\mathrm{MoO}_{3}-\mathrm{Al}, \mathrm{CO}_{3} \mathrm{O}_{4}-\mathrm{Al}\right.$ and $\left.\mathrm{V}_{2} \mathrm{O}_{5}-\mathrm{Al}\right)$ were selected for investigation, in which density differences between the products are different: compare $\rho_{\mathrm{Mo}}=$ $10.22 \mathrm{~g} / \mathrm{cm}^{3}, \rho_{\mathrm{Co}}=8.92 \mathrm{~g} / \mathrm{cm}^{3}, \rho_{\mathrm{V}}=6.11 \mathrm{~g} / \mathrm{cm}^{3}, \rho_{\mathrm{Al}_{2} \mathrm{O}_{3}}=2.8 \mathrm{~g} / \mathrm{cm}^{3}$. Both terrestrial and $\mu \mathrm{g}$ studies involving experiments under a wide range of conditions are currently in progress.

\section{ACKNOWLEDGEMENTS}

This work was supported by NASA grant NAG3-2213. We gratefully acknowledge the help of Mr. Robert Friedman and Peter Sunderland in managing the project.

\section{REFERENCES}

1. Merzhanov, A.G., and Borovinskaya, I.P., Dokl. Chem., 204: 429 (1972).

2. Moore, J.J., and Feng, H.J., Prog. Mater. Sci., 39: 243 (1995).

3. Varma, A., Rogachev, A., Mukasyan, A. and Hwang, Adv. Chem. Eng., 24: 79 (1998).

4. Varma, A, Sci. Amer. 283 (2): 58 (2000).

5. Mukasyan, A., Pelekh, A., Varma, A., Rogachev, A. \& Jenkins, A. AIAA J., 35: 1821 (1997).

6. Mukasyan, A., Pelekh, A. and Varma, A J. Mater. Syn. Proc. 5: 391 (1997).

7. Mukasyan, A., and Borovinskaya I. P., Intl. J. SHS., 1: 55 (1992).

8. Lau, C., Mukasyan, A., Pelekh, A. and Varma, A., J. Mat. Res., (2001,in press).

9. Merzhanov, A.G., Proc. II Eur. Symp.on Fluids in Space, Naples, Italy: 57 (1996).

10. Merzhanov, A.G., Rogachev, A.V., and Sytschev, A.E.. Dokl.Chem., 383: 45(1999).

11. Mukasyan, A.S., Lau, C. and Varma, A., Comb. Sci. Tech., (2001, in review). 